\title{
Coesão e atrito interno associados aos teores de carbono orgânico e de água de um solo franco arenoso
}

\author{
Cohesion and angle of internal friction associated with soil organic carbon and water content in \\ Hapludult
}

João Alfredo Braida ${ }^{\text {I }}$ José Miguel Reichert ${ }^{\text {II }}$ Dalvan José Reinert ${ }^{\text {II }}$ José Mário Doleys Soares ${ }^{\text {II }}$

\section{RESUMO}

Alterações na densidade, na estrutura e no teor de carbono orgânico do solo, produzidas pelo sistema de manejo, afetam os parâmetros da resistência ao cisalhamento. $O$ presente estudo foi proposto com o objetivo de avaliar os efeitos do acúmulo de carbono orgânico (CO) sobre a resistência ao cisalhamento de um Argissolo Vermelho Amarelo arênico. Amostras da camada superficial $(0-0,02 \mathrm{~m})$ do solo, com teor de CO variando entre 6,5 e 18,8g $\mathrm{kg}^{-1}$ e umidade equilibrada nas tensões de 6, 100 e $500 \mathrm{kPa}$, foram submetidas ao ensaio de cisalhamento direto, empregando-se tensões normais variando de 13,6 a 443,0kPa, determinando-se os valores de coesão e do ângulo de atrito interno. Além dos teores de CO, determinaram-se também a umidade gravimétrica, o grau de saturação de água e a densidade do solo das amostras. $O$ ângulo de atrito interno médio do solo foi de 32,5, 34,9 e 35,4 graus, enquanto que a coesão foi de 0,00, 1,06 e 7,95kPa, respectivamente, para amostras com umidade equilibrada nas tensões de 6, 100 e $500 \mathrm{kPa}$. Nas amostras mais secas (500kPa), o ângulo de atrito interno decresceu com o aumento do conteúdo de CO do solo. A coesão determinada pelo ensaio de cisalhamento direto mostrou-se independente do teor de carbono orgânico e decresceu com o aumento do teor de água do solo.

Palavras-chave: cisalhamento do solo, matéria orgânica do solo, estrutura do solo, mecânica do solo.

\section{ABSTRACT}

Changes in soil structure, bulk density and organic carbon content, caused by tillage systems, affect shear strength parameters. The present study was proposed with the objective of evaluating the effects of increased in soil organic carbon (SOC) content on the shear strength of an Hapludult (Argissolo
Vermelho Amarelo arênico, Brazil System). Soil surface samples (0-0.02 m), with SOC content varying from 6.5 to $18.8 \mathrm{~g} \mathrm{~kg}^{-1}$ and soil moisture equilibrated at tensions of 6,100 and $500 \mathrm{kPa}$, were submitted to the direct shear tests with normal tensions varying from 13.6 to $443.0 \mathrm{kPa}$. Cohesion and angle of internal friction values were determined. Besides SOC content, the water content, the saturation degree and the soil bulk density of the samples were determined. The angle of internal friction was of 32.5, 34.9 and 35.4 degrees, while the cohesion was of 0.00, 1.06 and $7.95 \mathrm{kPa}$, respectively for the samples with moisture at 6, 100 and $500 \mathrm{kPa}$ tension. In the driest samples $(500 \mathrm{kPa})$, the angle of internal attrition decreased with the increase of the SOC content. The cohesion determined in the direct shear tests was independent of the SOC content. However, the cohesion decreased with the increase of the soil water content.

Key words: soil shearing, soil organic matter, soil structure, soil mechanics.

\section{INTRODUÇÃO}

A resistência do solo ao cisalhamento pode ser expressa pela equação de Coulomb ( $\tau=c+\sigma t g \phi$ ). Nessa equação, os parâmetros c e $\phi$ representam, respectivamente, a coesão e o coeficiente de atrito entre as partículas do solo. Esses parâmetros são características intrínsecas do solo, sendo determinados por suas propriedades e atributos, tais como textura, estrutura, teor de matéria orgânica, densidade, mineralogia e teor de água (LEBERT \& HORN, 1991;

\footnotetext{
'Universidade Tecnológica Federal do Paraná (UTFPR), Campus Pato Branco, Laboratório de Física do Solo, 85501-970, Pato Branco, PR, Brasil. E-mail: braida@utfpr.edu.br. Autor para correspondência.

"Departamento de Solos, Universidade Federal de Santa Maria (UFSM), Centro de Ciências Rurais (CCR), 97105-900, Santa Maria, RS, Brasil.

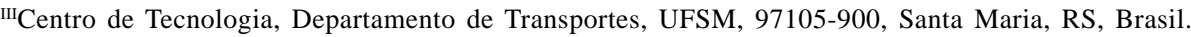


SCHJONNING 1991; ZHANG 1994; ROCHAet al., 2002; SILVA et al., 2004).

Assim, para um mesmo solo, espera-se que alterações de densidade, estrutura e teor de carbono orgânico, provocadas pelo sistema de manejo, possam resultar em alterações nos parâmetros da resistência ao cisalhamento. No sistema plantio direto, no qual o revolvimento do solo é praticamente inexistente, após alguns anos de cultivo, o solo adquire uma estrutura caracterizada por apresentar agregados mais densos, resistentes e próximos entre si (CHANEY et al., 1985). Além disso, nesse sistema, observa-se um aumento do teor de matéria orgânica do solo, especialmente na camada superficial (AMADO et al., 2001; LOVATO et al., 2004; CONCEIÇÃO et al., 2005).

Em geral, essas alterações observadas no sistema plantio direto tornam o solo mais resistente, capaz de suportar tráfego mais pesado sem apresentar deformação significativa. Essa maior resistência, geralmente, é associada à maior densidade do solo, mas é possível que parte desse efeito se deva ao incremento de carbono orgânico, especialmente pela influência deste sobre a coesão do solo.

A matéria orgânica atua sobre os parâmetros do cisalhamento de diferentes formas. Basicamente, espera-se um aumento da coesão entre as partículas do solo, resultante do aumento da força das ligações e/ou estabelecimento de novas ligações entre as mesmas, seja pelas características físicas e químicas das moléculas orgânicas, seja em função de enlaces de partículas produzidas por filamentos orgânicos como hifas de fungos e raízes (SOANE, 1990).

Ao reduzir a densidade do solo, a matéria orgânica pode diminuir o ângulo de atrito interno, por reduzir o número de pontos de contato entre as partículas e, ainda, por ser um material mais flexível e de menor dureza que as partículas minerais. No entanto, em baixos teores de água, as substâncias orgânicas, por reterem fortemente a água, podem aumentar a fricção entre as partículas (SOANE, 1990; ZHANG \& HARTGE, 1990).

A matéria orgânica pode ser associada a dois efeitos contraditórios sobre a resistência do solo: aumento da força de ligação entre as partículas minerais e mudança no arranjo das partículas - diminuição da densidade - (EKWUE, 1990; ZHANG, 1994, HORN \& LEBERT, 1994). O aumento ou redução da resistência do solo dependerá do balanço entre seus efeitos conjuntos sobre a densidade, os parâmetros de cisalhamento, a tensão capilar e o grau de saturação de água (ZHANG et al., 1997).

$\mathrm{Na}$ literatura, encontram-se resultados contraditórios, mostrando situações em que maiores teores de matéria orgânica são acompanhados de diminuição da resistência ao cisalhamento do solo (OHU et al., 1985; OHU et al., 1986; EKWUE, 1990) e outros nos quais essa aumenta (DAVIES, 1985; EKWUE,1990). Provavelmente, essas diferenças são devidas à origem da matéria orgânica (EKWUE, 1990), ao tempo decorrido após a incorporação da matéria orgânica, ao teor de água no solo (DAVIES, 1985; ZHANG \& HARTGE, 1990) e à textura do solo. Considerando, ainda, que o comportamento mecânico do solo é dependente do comportamento mecânico de seus agregados (HORN, 1990), é possível que parte dos resultados contraditórios existentes na literatura sejam produzidos por diferenças estruturais das amostras avaliadas.

Para solos agregados, a envoltória de MohrCoulomb pode ser dividida em dois segmentos, com declividades e interceptos diferentes e, segundo LEBERT \& HORN (1991), isso está relacionado à resistência dos agregados do solo. Assim, uma primeira envoltória, mais inclinada e com intercepto menor, representaria a envoltória de ruptura definida pelo atrito e pela coesão interagregados (maior atrito e menor coesão). Por outro lado, a segunda envoltória seria definida pelo atrito e pela coesão intra-agregados (menor atrito e maior coesão), que só se manifestariam quando os agregados fossem rompidos, ou seja, quando fossem empregadas tensões normais maiores que a resistência dos agregados, conforme observado por CARPENEDO(1994) e GAGGERO(1998).

O presente estudo foi proposto com o objetivo de avaliar a resistência ao cisalhamento de amostras de um Argissolo com diferentes teores de carbono orgânico e água, buscando-se verificar se os parâmetros do cisalhamento são afetados pelo acúmulo de matéria orgânica no solo e pelo o teor de água do solo.

\section{MATERIAL E MÉTODOS}

O presente estudo foi realizado no Laboratório de Materiais de Construção Civil (LMCC) e no Laboratório de Física do Solo da UFSM, a partir de amostras de um Argissolo Vermelho Amarelo arênico, com densidade de partículas de 2,58Mg m ${ }^{-3}$ e 155, 216 e $629 \mathrm{~g} \mathrm{~kg}^{-1}$ de argila, silte e areia, respectivamente, na camada superficial ( 0 a $0,05 \mathrm{~m})$. As amostras foram coletadas na área experimental do Departamento de Solos da UFSM, no município de Santa Maria - RS.

Com o objetivo de obterem-se amostras com ampla variação do teor de carbono orgânico, as coletas foram realizadas em cinco áreas próximas umas das outras. A escolha dessas áreas de amostragem levou 
em consideração uma análise prévia do teor de carbono orgânico do solo (CO), na qual observaram-se teores de 6,5 a 18,8g kg-1 de CO. Quatro áreas constituíam-se de parcelas de um experimento, cujos tratamentos são combinações de doses de esterco líquido de suínos e plantas de cobertura no sistema plantio direto (GIACOMINI, 2001), enquanto que a quinta era uma área contígua ao experimento cultivada ocasionalmente. O histórico de cultivo de cada área de amostragem, nos quatro anos que antecederam a coleta, pode ser assim resumido:

1. Sucessão aveia/milho, sem utilização de esterco líquido de suíno (ELS);

2. Sucessão aveia/milho, com aplicação de $80 \mathrm{~m}^{3}$ ha $^{-1}$ de ELS no milho;

3. Sucessão aveia + ervilhaca/milho, com aplicação de $40 \mathrm{~m}^{3}$ ha $^{-1}$ de ELS no milho;

4. Sucessão aveia + ervilhaca/milho, com aplicação de $80 \mathrm{~m}^{3}$ ha $^{-1}$ de ELS no milho;

5. Pousio invernal, com cultivo ocasional de milho no verão sem utilização de fertilizantes.

As amostras foram coletadas na camada superficial (0 a 0,02m de profundidade). Em novembro de 2002, fez-se a primeira coleta, na qual foram tomadas 18 amostras por área de amostragem. No laboratório, as amostras, obtidas em cada área de amostragem, foram divididas em conjuntos de seis amostras que, depois de equilibradas nas tensões de 6,100 ou $500 \mathrm{kPa}$, foram submetidas ao ensaio de cisalhamento direto. Nesses ensaios, aplicaram-se pressões de 13,6; 27,3; 54,8; 148,4; 295,7 e 443,0kPa. Com base nos resultados obtidos com as amostras da primeira coleta, efetuouse uma segunda coleta, em abril de 2003, tomando-se 12 amostras em cada área de amostragem, que, depois de equilibradas nas tensões de 6,100 ou $500 \mathrm{kPa}$, foram submetidas ao ensaio de cisalhamento direto com as pressões normais de 27,3; 54,8; 148,4 e 295,7kPa.

Os ensaios de cisalhamento direto foram realizados em uma prensa de cisalhamento direto TESTOP RONALD motorizada, empregando-se uma velocidade de deslocamento horizontal de $0,25 \mathrm{~mm} \mathrm{~min}^{-1}$, com um deslocamento horizontal máximo de $15 \mathrm{~mm}$. As cargas normais foram aplicadas 5 minutos antes de iniciar efetivamente o ensaio de cisalhamento. Os parâmetros de resistência ao cisalhamento, coesão e ângulo de atrito interno foram calculados conforme proposto por LAMBE \& WHITMAN (1979).

Após o ensaio, tomou-se uma subamostra do material de solo, que foi submetida à análise do teor de carbono orgânico pelo método descrito em EMBRAPA (1997). Foram calculados, ainda, a densidade do solo, a umidade gravimétrica, o grau de saturação de água e a porosidade total de cada amostra, com base em pesagens realizadas, na densidade de partículas e nas dimensões das caixas de cisalhamento.

Para a análise estatística, primeiro avaliouse o efeito do teor de água, considerando-se um delineamento completamente casualizado, com três tratamentos (3 tensões de água) e 10 repetições. Para a análise da variância da variável coesão, que apresentou valores iguais a zero, os dados foram transformados fazendo-se $y^{\prime}=\sqrt{y+0,5}$. Depois, para avaliação das relações entre coesão e ângulo de atrito interno com o teor de CO, foram realizados estudos de correlações entre essas variáveis, fazendo-se o ajuste de equações. Os ajustes significativos são indicados por asteriscos colocados junto ao coeficiente de determinação das equações, sendo um e dois asteriscos para os níveis de 5 e $1 \%$, respectivamente.

\section{RESULTADOS E DISCUSSÃO}

As envoltórias de resistência ao cisalhamento (Figura 1), para todas as tensões estudadas, apresentaram uma inclinação constante ao longo de toda a faixa de pressões normais utilizadas. Isso acontece porque, neste solo, a agregação é fraca, especialmente na sua camada superficial, que contém cerca de $629 \mathrm{~g} \mathrm{~kg}^{-1}$ de areia e apenas $155 \mathrm{~g} \mathrm{~kg}^{-1}$ de argila. Assim, os agregados não apresentam resistência suficiente para produzir mudanças significativas na inclinação e no intercepto da envoltória, como observado por LEBERT \& HORN (1991). Portanto, pode-se afirmar que mesmo as pressões normais mais baixas empregadas $(14 \mathrm{kPa})$ seriam suficientes para romper os agregados desse solo, de maneira que a envoltória de resistência é definida exclusivamente por suas características granulométricas. CARPENEDO (1994), quando trabalhou com amostras de um Podzólico Vermelho Escuro (Argissolo Vermelho distrófico típico) e de um Podzólico Vermelho Amarelo (Argissolo Vermelho distrófico arênico) com apenas 16 e 8\% de argila, respectivamente, também não observou efeitos da agregação na envoltória de cisalhamento. Por outro lado, quando CARPENEDO (1994) usou amostras de um Latossolo Roxo distrófico (Latossolo Vermelho distroférrico típico), com $62 \%$ de argila, e quando GAGGERO (1998) trabalhou com amostras de um Podzólico Vermelho Escuro (Argissolo Vermelho distrófico típico), com $18 \%$ de argila, esses efeitos foram observados.

Os valores médios da densidade, do teor de carbono orgânico, da umidade gravimétrica, do grau de saturação de água, da porosidade total, do ângulo de atrito interno e da coesão do solo, para cada tensão 


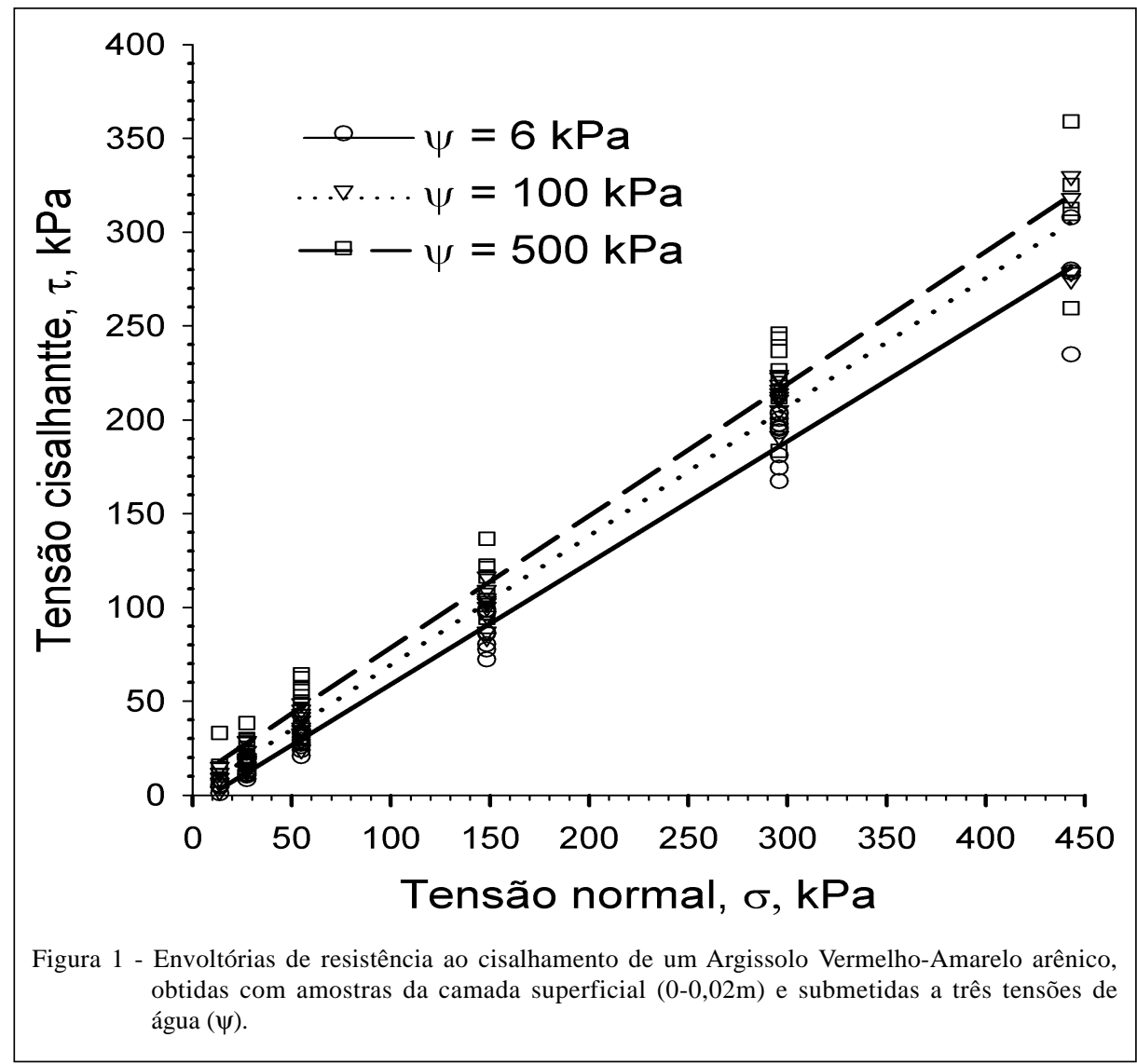

de água usada, são apresentados na tabela 1. O ângulo de atrito interno e a coesão apresentaram variação significativa em função da tensão de água no solo, tornando-se maiores à medida que o solo se tornava mais seco.

O efeito da tensão de água sobre o ângulo de atrito interno está associado ao efeito lubrificante que a água exerce quando recobre as partículas sólidas. Assim, à medida que a tensão aplicada sobre a água do solo aumenta, os filmes de água existentes sobre as partículas vão se desfazendo, reduzindo seu efeito lubrificante e, portanto, aumentando o atrito entre as mesmas. As relações do $\phi$ com a Ug e com o Gs indicam que o $\phi$ decresce com o aumento do conteúdo de água dentro da faixa estudada (Figura 2).

Para as tensões de água de 6 e $100 \mathrm{kPa}$, o ângulo de atrito interno não variou com a variação do teor de CO, mas, para a tensão de $500 \mathrm{kPa}$, houve uma tendência significativa de diminuição desse atrito conforme o aumetava o teor de CO do solo (Figura 3). Teoricamente, o aumento do teor de matéria orgânica poderia aumentar o atrito, já que as partículas orgânicas reteriam a água existente no solo junto de si, dificultando a formação de películas de água sobre as partículas minerais. Nas tensões de água menores, isso não

Tabela 1 - Densidade do solo (Ds), teor de carbono orgânico (CO), umidade gravimétrica (Ug), grau de saturação de água (Gs), porosidade total (Pt), ângulo de atrito interno $(\phi)$ e coesão (c) em amostras da camada de $0,0-0,02 \mathrm{~m}$ de um Argissolo Vermelho Amarelo arênico de textura superficial franco-arenosa, para três tensões de água (médias de 10 repetições).

\begin{tabular}{lllccccc}
\hline Tensão & Ds & CO & Ug & Gs & Pt & c \\
\hline $\mathrm{kPa}$ & $\mathrm{Mg} \mathrm{m}^{-3}$ & $\mathrm{~g} \mathrm{~kg}^{-1}$ & $\mathrm{~g} \mathrm{~g}^{-1}$ & $\%$ & $\%$ & graus & $\mathrm{kPa}$ \\
6 & $1,37 \mathrm{~ns}^{*}$ & $14,0 \mathrm{~ns}$ & $0,21 \mathrm{a}^{* *}$ & $62,7 \mathrm{a}$ & $46,6 \mathrm{~ns}$ & $32,5 \mathrm{~b}$ & $0,00 \mathrm{~b}$ \\
100 & 1,36 & 14,5 & $0,14 \mathrm{~b}$ & $39,1 \mathrm{~b}$ & 47,1 & $34,9 \mathrm{a}$ & $1,06 \mathrm{~b}$ \\
500 & 1,35 & 12,5 & $0,09 \mathrm{c}$ & $24,6 \mathrm{c}$ & 47,4 & $35,4 \mathrm{a}$ \\
\hline
\end{tabular}

* ns = não-significativo - não se observou variância significativa $(\mathrm{P}<0,05)$, pelo teste $\mathrm{F}$, em função da tensão de água.

** Médias seguidas de letras distintas, na mesma coluna, são estatisticamente diferentes $(\mathrm{P}<0,05)$ pelo teste DMS.

Ciência Rural, v.37, n.6, nov-dez, 2007. 

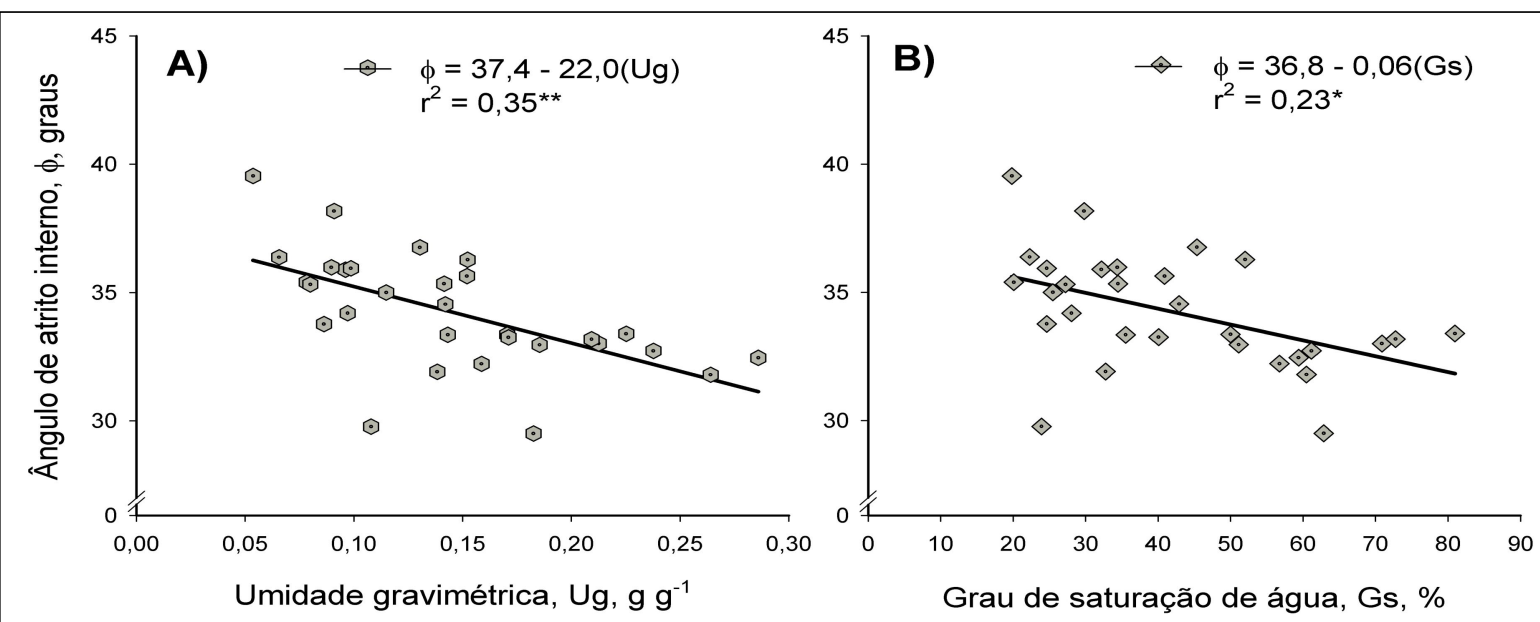

Figura 2 - Ângulo de atrito interno $(\phi)$ de um Argissolo Vermelho-Amarelo arênico, determinado com amostras da camada superficial $(0-0,02 \mathrm{~m})$, como função: A) da umidade gravimétrica (** modelo ajustado significativo a $\mathrm{P} \leq 0,01$, pelo teste F); B) do grau de saturação de água (* modelo ajustado significativo a $\mathrm{P} \leq 0,05$, pelo teste F) .

acontece porque, provavelmente, a quantidade de água existente é suficiente para suprir a demanda de água da MO e, ainda, para formar filmes lubrificantes sobre todas as partículas minerais.

$\mathrm{Na}$ tensão de água igual a $500 \mathrm{kPa}$, o incremento de MO do solo é associado a uma redução do $\phi$ (Figura 3), provavelmente porque o incremento de MO resultou em redução da densidade (Figura 4a) e em aumento do teor de água em uma mesma tensão (Figura 4b). A redução da densidade do solo significa redução do número de pontos de contato entre as partículas e, portanto, do atrito entre elas. Com relação ao aumento da água retida em uma mesma tensão, devese considerar que, à medida que temos mais matéria orgânica no solo, provavelmente sua distribuição entre as partículas minerais será mais uniforme. Assim, se

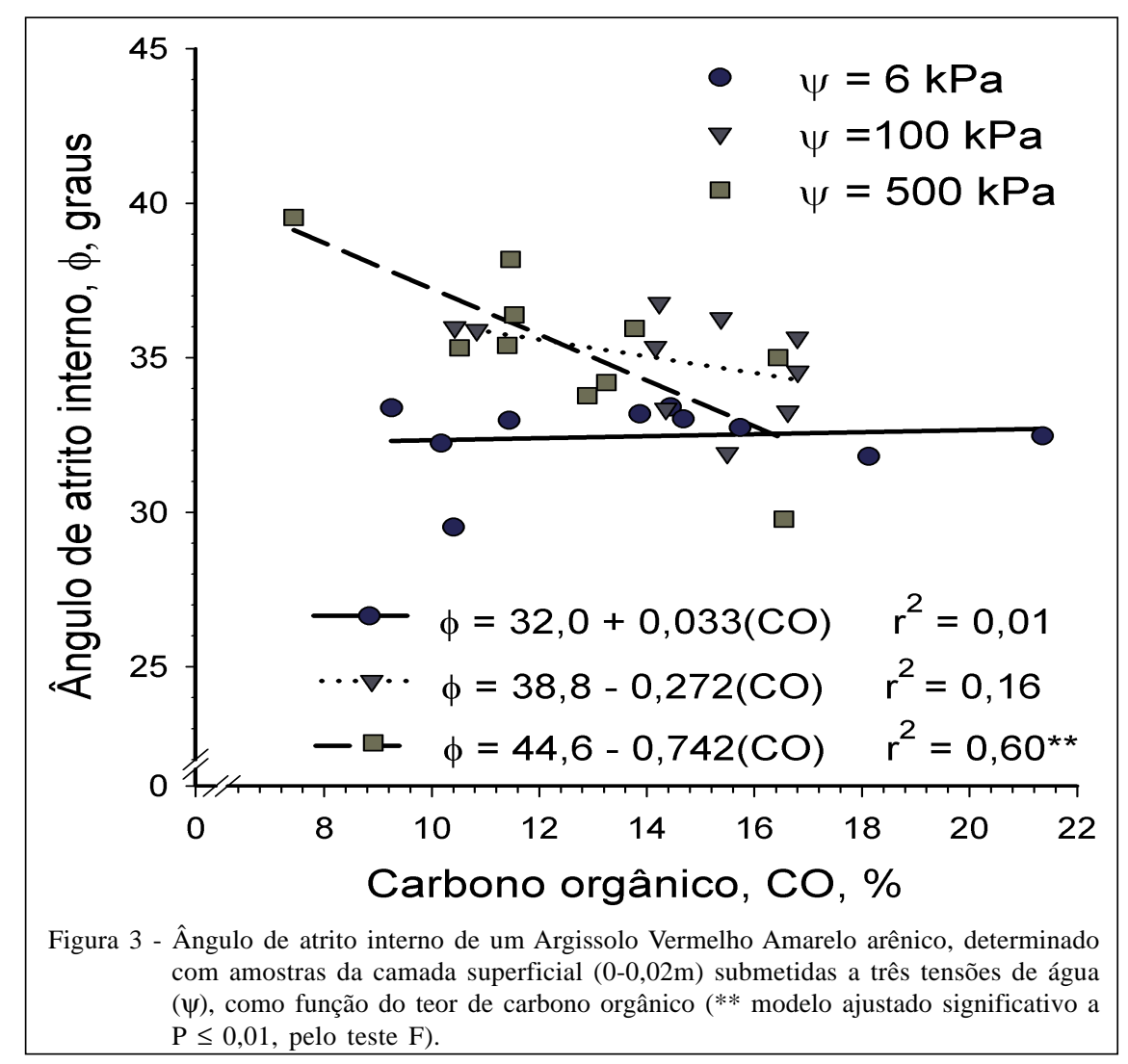

Ciência Rural, v.37, n.6, nov-dez, 2007. 

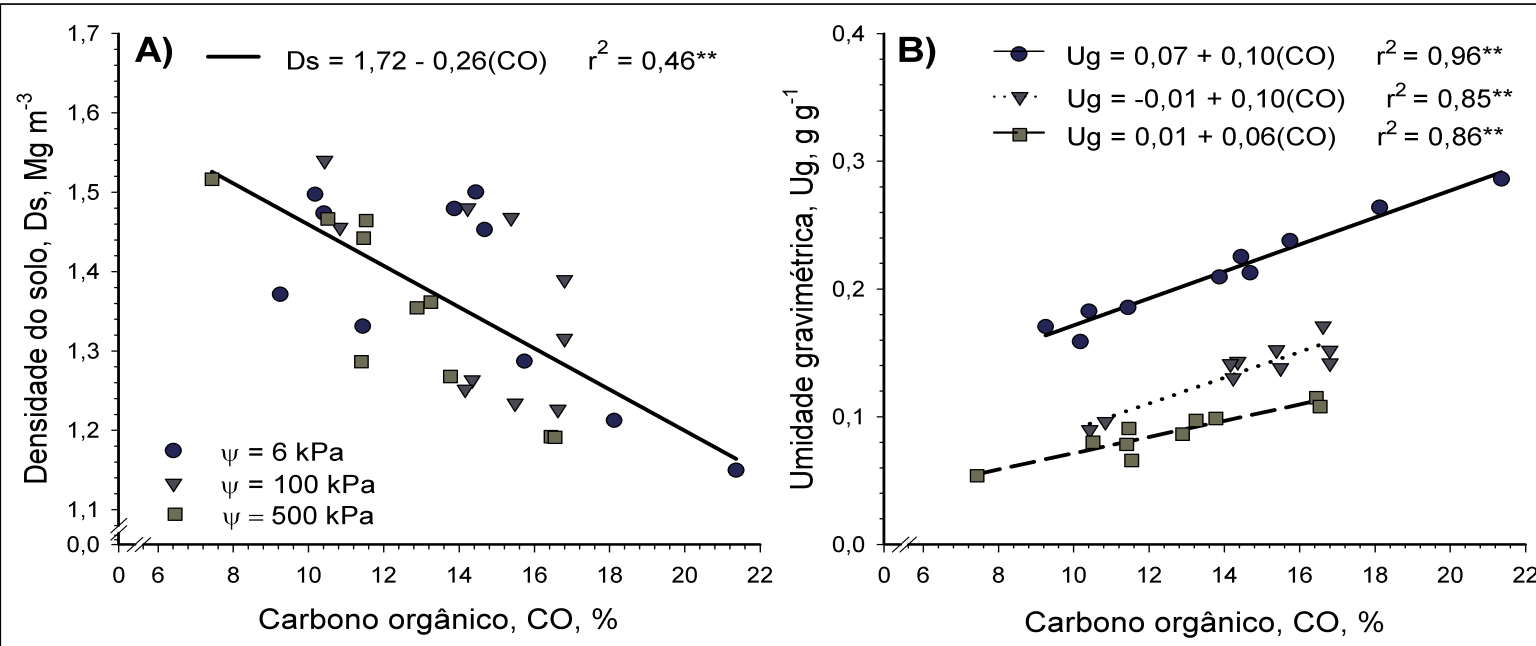

Figura 4 - Densidade do solo (A) e umidade gravimétrica (B) de um Argissolo Vermelho Amarelo arênico, medidas em amostras da camada superficial $(0-0,02 \mathrm{~m})$ e submetidas a três tensões de água $(\psi)$, como função do teor de carbono orgânico $(* *$ modelo ajustado significativo a $\mathrm{P} \leq 0,01$ pelo teste $\mathrm{F}$ ).

existe mais matéria orgânica e mais água e se elas estão distribuídas mais uniformemente sobre as partículas minerais, então é possível que exista uma redução do atrito, como foi observado no presente trabalho.

A coesão do solo variou significativamente com a variação da tensão da água nas amostras, tornando-se menor à medida que essa diminuiu. Na tensão de $6 \mathrm{kPa}$, o solo não apresentou coesão significativa. Na figura 5 , observa-se que a coesão decresce rapidamente para teores de água até cerca de $0,15 \mathrm{~g} \mathrm{~g}^{-1}$ ou para grau de saturação até cerca de $35 \%$.
Provavelmente, isso aconteça porque os teores de argila e carbono orgânico deste solo sejam suficientes para estabelecer um efeito cimentante entre os grãos de areia, conferindo-lhe uma coesão relativamente alta quando seco. No entanto, essa coesão é facilmente suprimida com a hidratação do sistema.

Além disso, em baixos teores de água, provavelmente exista uma maior coesão aparente, resultante da formação de meniscos de água nos pontos de contato entre as partículas. À medida que o teor de água vai aumentando, essa coesão aparente vai
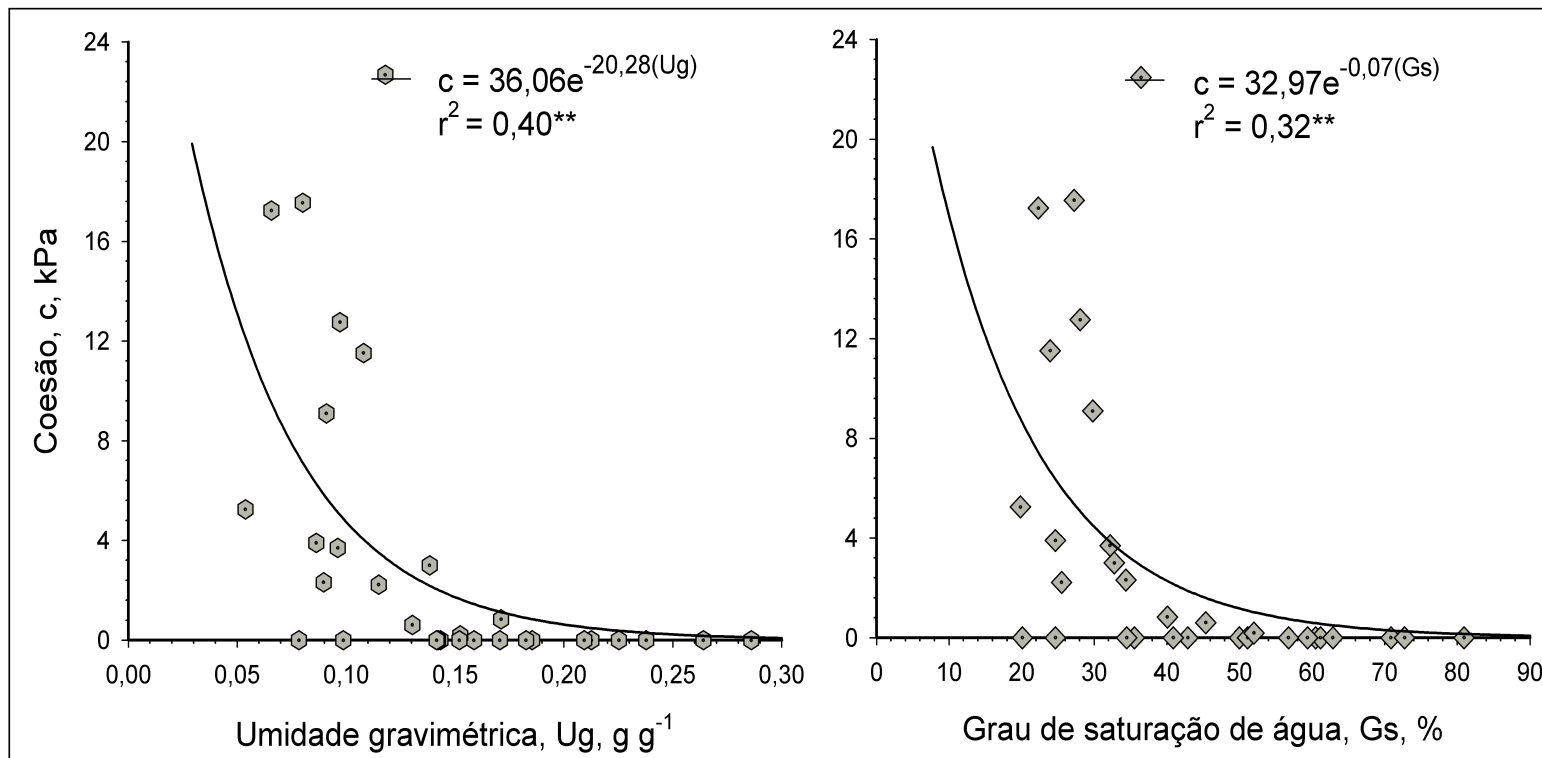

Figura 5 - Coesão do solo de um Argissolo Vermelho Amarelo arênico, determinada com amostras da camada superficial (0$0,02 \mathrm{~m}$ ), como função da umidade gravimétrica e do grau de saturação de água (** modelo ajustado significativo a $\mathrm{P} \leq 0,01$ pelo teste $\mathrm{F})$. 
diminuindo devido à redução da curvatura dos meniscos de água. ZHANG \& HARTGE (1990), em trabalho com solo arenoso, observaram que a coesão cresceu com o aumento da tensão de água no solo até que essa atingiu um valor entre 4 e $7 \mathrm{kPa}$, tornando-se decrescente depois disso. Provavelmente, naquele solo, os teores de matéria orgânica e de argila eram insuficientes para produzir coesão significativa entre as partículas de areia quando o solo se encontrava seco. Assim, a coesão observada era quase que exclusivamente devida ao efeito da formação de meniscos de água nos pontos de contato, existindo uma umidade que propicia uma combinação de número e de curvatura de meniscos que resulta num valor máximo de coesão aparente. No solo usado no presente estudo, no entanto, as quantidades de argila e matéria orgânica existentes resultam em uma forte coesão do solo quando este está seco e, por isso, a coesão é sempre decrescente com o aumento do teor de água.

Apesar de o teor de matéria orgânica poder estar contribuindo para o desenvolvimento da coesão verdadeira deste solo, não se verificou correlação significativa entre o teor de CO e a coesão determinada pelo ensaio de cisalhamento direto. Provavelmente isso ocorra em função dos efeitos da MO sobre a densidade e a retenção de água do solo (Figura 4). O aumento no teor de CO resultou sempre em redução da densidade do solo, diluindo qualquer possível efeito positivo sobre a coesão.

\section{CONCLUSÕES}

Para o Argissolo Vermelho-Amarelo arênico empregado, a envoltória de resistência ao cisalhamento é única em toda a faixa de cargas normais empregadas (14 a 450kPa). O ângulo de atrito interno é afetado pelo teor de matéria orgânica do solo, mas isso está relacionado ao teor de água do solo. A coesão determinada pelo ensaio de cisalhamento direto é independente do teor de matéria orgânica e decresce com o aumento do teor de água do solo.

\section{AGRADECIMENTOS}

À Fundação de Amparo à Pesquisa do Rio Grande do Sul (FAPERGS) e ao Conselho Nacional de Desenvolvimento Científico e Tecnológico (CNPq), pelo financiamento parcial. Aos colegas Celso Aita e Sandro José Giacomini, do Departamento de Solos da Universidade Federal de Santa Maria, que cederam o experimento para a coleta das amostras de solos utilizadas neste estudo.

\section{REFERÊNCIAS}

AMADO, T.J.C. et al. Potencial de culturas de cobertura em acumular carbono e nitrogênio no solo no plantio direto e a melhoria da qualidade ambiental. R Bras Ci Solo, v.25, n.1, p.189-197, 2001.

CARPENEDO, V. Compressibilidade de solos em sistemas de manejo. 1994. 106f. Tese (Doutorado em Ciência do Solo) - Curso de Doutorado em Ciência do Solo, Universidade Federal do Rio Grande do Sul.

CHANEY, K. et al. The effects of direct drilling, shallow cultivation and ploughing on some soil physical properties in a long-term experiment on spring barley. J Agr Sci, v.104, n.1, p.125-133, 1985.

CONCEIÇÃO, P.C. et al. Qualidade do solo em sistemas de manejo avaliada pela dinâmica da matéria orgânica e atributos relacionados. R Bras Ci Solo, v.29, n.5, p.777-788, 2005.

DAVIES, P. Influence of organic matter content, moisture status and time after reworking on soil shear strength. J Soil Sci, v.36, n.2, p.299-306. 1985.

EKWUE, E.I. Organic matter effects on soil strength properties. Soil Tillage Res, v.16, n.33, p.289-297, 1990.

EMBRAPA. Manual de métodos de análise de solos. 2.ed. rev. e atual. Rio de Janeiro: EMBRAPA, 1997. 212p.

GAGGERO, M.R. Alterações das propriedades físicas e mecânicas do solo sob sistemas de preparo e pastejo. 1998. 125f. Dissertação (Mestrado em Ciência do Solo) Curso de Mestrado em Ciência do Solo, Universidade Federal do Rio Grande do Sul.

GIACOMINI, S.J. Consorciação de plantas de cobertura no outono/inverno e fornecimento de nitrogênio ao milho em sistema plantio direto. 2001. 124f. Dissertação (Mestrado em Agronomia) - Curso de Mestrado em Agronomia, Universidade Federal de Santa Maria.

HORN, R. Aggregate characterization as compared to soil bulk properties. Soil Tillage Res, v.17, p.265-289, 1990.

HORN, R.; LEBERT, M. Soil compactability and compressibility. In: SOANE, B.D.; OUWERKERK, C. VAN. (Edi.). Soil compaction in crop production. Amsterdam: Elsevier, 1994. 662p.

LAMBE, T.W.; WHITMAN, R.V. Soil Mechanics, SI Version. New York: J. Wiley \& Sons, 1979. 553p. (Series in soil engineering).

LEBERT, M.; HORN, R. A method to predict the mechanical strength of agricultural soils. Soil Tillage Res, v.19, p.275286, 1991.

LOVATO, T. et al. Adição de carbono e nitrogênio e sua relação com os estoques no solo e com o rendimento do milho em sistemas de manejo. R Bras Ci Solo, v.28, n.1, p.175-187, 2004.

OHU, O.J. et al. Peatmoss effect on the physical and hydraulic characteristics of compacted soils. Trans Am Soc Agric Eng, v.28, p.420-424, 1985. 
OHU, O.J. et al. Shear strength prediction of soils with varying added organic matter contents. Trans Am Soc Agric Eng, v.29, p.351-355, 1986.

ROCHA, W.W. et al. Resistência ao cisalhamento e grau de intemperismo de cinco solos na região de Lavras (MG). R Bras Ci Solo, v.26, n.2, p.297-303, 2002.

SCHJONNING, P. Soil strength as influenced by texture, water content and soil management. Soil Tillage Res, v.12, p.277283, 1991.

SILVA, R. B. et al. Resistência ao cisalhamento de um Latossolo sob diferentes usos e manejo R Bras Ci Solo, v.28, n.1, p.165173, 2004
SOANE, B.D. The role of organic matter in soil compactability: a review of some practical aspects. Soil Tillage Res, v.16, p.179-201, 1990.

ZHANG, H. Organic matter incorporation affects mechanical properties of soil aggregates. Soil Tillage Res, v.31, p.263275, 1994.

ZHANG, H. et al. Effectiveness of organic matter incorporation in reducing soil compactability. Soil Sci Soc Am J, v.61, p.239245, 1997.

ZHANG, H.Q.; HARTGE, K.H. Cohesion in unsaturated sandy soils and the influence of organic matter. Soil Techn, v.3, p.311-326, 1990. 